\title{
A clear cell adenocarcinoma of the gallbladder with hepatoid differentiation: case report and review of literature
}

This article was published in the following Dove Press journal:

OncoTargets and Therapy

22 September 2016

Number of times this article has been viewed

\author{
Chengsheng Zhang ${ }^{1,2}$ \\ Wei Zhang ${ }^{1,2}$ \\ Dianbin $\mathrm{Mu}^{\prime}$ \\ Xuetao Shi' \\ Lei Zhao',2 \\ 'Department of Hepatobiliary Surgery, \\ Shandong Cancer Hospital affiliated \\ to Shandong University, Shandong \\ Academy of Medical Science, ${ }^{2}$ School \\ of Medicine and Life Sciences, \\ University of Jinan-Shandong Academy \\ of Medical Sciences, Jinan, Shandong \\ Province, People's Republic of China
}

Correspondence: Lei Zhao

Department of Hepatobiliary Surgery, Shandong Cancer Hospital affiliated to Shandong University, Shandong Academy of Medical Science, No 440 Jiyan Road, Jinan City, Shandong Province 250II7, People's Republic of China

Tel +8653 I 67626368

Email drzhaolei@hotmail.com
Abstract: An 80-year-old male was referred to our department for a gallbladder mass. He denied any history of alcohol consumption or cholecystitis and smoking. Hepatitis B surface antigen test and antihepatitis $\mathrm{C}$ antibody test were found to be negative. Serum carbohydrate antigen 19-9 (CA19-9) and carcinoembryonic antigen were elevated (CA19-9 was $59.92 \mathrm{U} / \mathrm{mL}$ and carcinoembryonic antigen was $12.64 \mathrm{ng} / \mathrm{mL}$ ), whereas alpha-fetoprotein was below the normal limit $(2.46 \mathrm{ng} / \mathrm{mL})$. Computed tomography scan revealed a solid mass with measurements of $4.6 \times 5.6 \times 7.1 \mathrm{~cm}$, which nearly filled the whole gallbladder space. Radical cholecystectomy, including segments IV B and V of the liver and lymphadenectomy, was performed. The neoplasm in gallbladder was completely resected, and the patient obtained a negative margin. Histological and immunohistochemical profile suggested a clear cell adenocarcinoma of the gallbladder with hepatoid differentiation. After reviewing the literature, we reported that this case is the first identified case of cell adenocarcinoma of the gallbladder with extensive hepatoid differentiation. However, clinical features of clear cell adenocarcinoma with hepatoid differentiation remain unclear due to the extremely rare incidence. There was no indication of adjuvant chemotherapy and no literature has been reported on the application of chemotherapy. This case showed a promising clinical outcome after curative resection, which indicated that surgical treatment could be potentially considered for suitable patients.

Keywords: gallbladder, clear cell adenocarcinoma, hepatoid differentiation

\section{Background}

Clear cell adenocarcinoma of the gallbladder (CCG) is a very rare malignant neoplasm ${ }^{1}$ that has been recognized by the World Health Organization (WHO) as a distinctive type of gallbladder and extrahepatic bile duct tumor. ${ }^{2} \mathrm{CCG}$ originates from gallbladder epithelium. Nearly all the reported CCG patients were female, with a mean age of 60 years at diagnosis. In addition, hepatoid adenocarcinoma is an uncommon extrahepatic tumor with morphologic characteristics that are similar to hepatocellular carcinoma. ${ }^{3,4} \mathrm{CCG}$ with extensive hepatoid differentiation has never been reported. Though the etiology of CCG is complicated, the potential cause of CCG has been shown to be associated with gallstones. In this case report, we investigated a case of CCG with hepatoid differentiation and reviewed the relevant literature. A license from the Shandong Tumor Hospital and Institute Ethical Committee was obtained. Written informed consent was obtained from the patient for publication of this case report and accompanying images. 

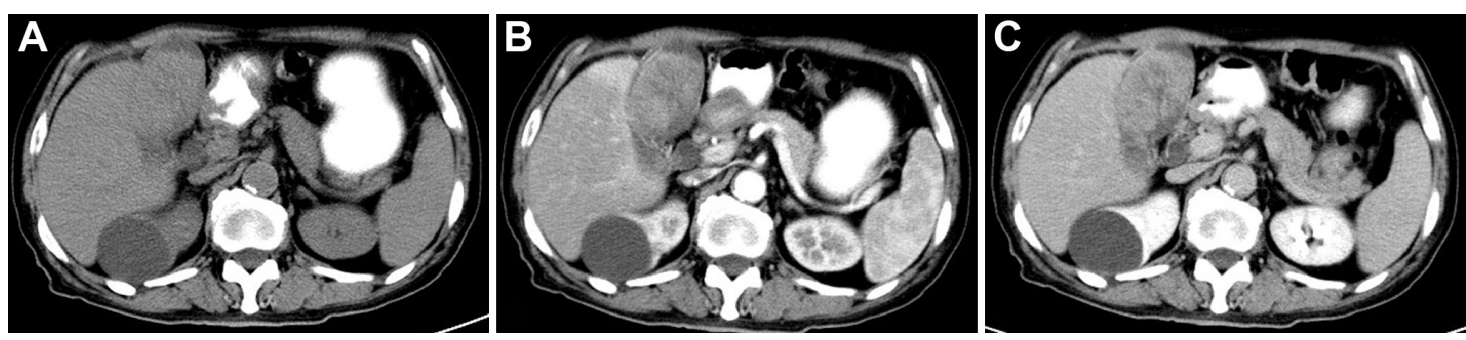

Figure I Enhanced CT scan.

Notes: (A) On unenhanced CT, the mass was slightly hypoattenuating and had a fuzzy edge, containing irregular, hypodense regions. On contrast-enhanced CT scan, the mass exhibited moderately inhomogeneous enhancement during the arterial phase (B), portal venous phase, and delayed phase (C).

Abbreviation: CT, computer tomography.

\section{Case presentation}

An 80-year-old male was referred to our department with a gallbladder mass. The patient described a 3-month history of dull pain in the right hypochondrial region (especially after meals), accompanied by a radiating pain to the right back shoulder, tiredness and drowsy, and loss of appetite. Abdominal ultrasonography revealed a neoplastic lesion in his gallbladder, which was confirmed by computed tomography (CT) scan. He denied any history of hepatitis or alcohol consumption. The levels of serum carbohydrate antigen 19-9 (CA19-9) and carcinoembryonic antigen (CEA) were elevated (CA19-9 was $59.92 \mathrm{U} / \mathrm{mL}$ with reference range $0-39 \mathrm{U} / \mathrm{mL}$ and CEA was $12.64 \mathrm{ng} / \mathrm{mL}$ with reference ranges $0.0-3.4 \mathrm{ng} / \mathrm{mL}$ ). Liver function tests indicated a slight elevation in conjugated bilirubin (conjugated bilirubin, $8.8 \mu \mathrm{mol} / \mathrm{L}$, reference range $0-3.4 \mu \mathrm{mol} / \mathrm{L}$ and unconjugated bilirubin, $6.4 \mu \mathrm{mol} / \mathrm{L}$, reference range $1.7-10.2 \mu \mathrm{mol} / \mathrm{L}$ ); the levels of both alkaline phosphatase and $\gamma$-glutamyl transpeptidase were elevated (alkaline phosphatase, $179 \mathrm{U} / \mathrm{L}$, reference range $45-125 \mathrm{U} / \mathrm{L}$ and $\gamma$-glutamyl transpeptidase, $148 \mathrm{U} / \mathrm{L}$, reference range 10-60 U/L), whereas the levels of alanine transaminase and aspartate transaminase were within normal ranges. A CT scan that was performed at our institution revealed a heterogeneous mass measuring $7.1 \times 5.6 \times 4.6 \mathrm{~cm}$, which nearly occupied the gallbladder. On unenhanced $\mathrm{CT}$, the mass was slightly hypoattenuating and had a fuzzy edge, containing irregular, hypodense regions. On contrast-enhanced CT scan, the mass exhibited moderately inhomogeneous enhancement during the arterial phase, portal venous phase, and delayed phase (Figure 1). The irregular hypodense regions in the unenhanced CT showed no enhancement in the arterial and portal phases. Based on the abovementioned results, we diagnosed it as a gallbladder cancer. At surgery, we found that the mass was located inside the gallbladder and nearly occupied the gallbladder space. The common bile duct was dilatant, and the gallbladder serosa was infiltrated but without any visible or direct hepatic invasion (tumor invades no extension beyond the serosa on naked eye).

Besides, initial exploration found no lymph node metastases in the celiac axis, aortocaval groove, and any other places. According to the seventh edition of the American Joint Committee on Cancer (AJCC) cancer staging manual, the patient was classified as T2N0M0 during the surgery. Radical resection (cholecystectomy + en bloc hepatic resection + lymphadenectomy) of the gallbladder adenocarcinoma was performed to remove the mass. This included resection of gallbladder and wedge resection of the gallbladder fossa (parts of segments IV B and V of the liver) and lymphadenectomy. The cystic duct was resected at its junction with the common bile duct, and frozen section showed negative margin of the cystic duct. Lymphadenectomy was performed to clear all the lymph nodes within the porta hepatis, nodes along the common bile duct, cystic duct, hepatic artery, and portal vein, nodes behind the pancreatic head and the duodenum, and nodes posterior to the portal vein. The following procedures were carried out during lymphadenectomy: 1) dissection of the lymph nodes behind the pancreatic head and the duodenum; 2) skeletonization of the common hepatic artery; 3) skeletonization of the common bile duct; and 4) dissection of the anterior surface of the portal vein. Pathological examination showed that the regional lymph node exhibited metastasis, and the tumor perforated the serosa to the surrounding adipose tissue, but not yet reached the liver. Accordingly, the cancer staging was reevaluated as pT3N1M0, stage IIIB. This patient recovered without any complications. Two weeks after the surgery, serum CEA and CA19-9 returned to normal levels. The neoplasm was pathologically confirmed as CCG with hepatoid differentiation. Written informed consent was obtained from the patient.

\section{Gross appearance}

The gross appearance of CCG in this case consisted of lobulated, golden yellow mucus circumscribed, firm gray-red 
masses. The fundus of the tumor was located in the body of the gallbladder fossa side (Figure 1). Images using light microscopy indicated that the tumor invaded through all layers of gallbladder wall, as well the surrounding adipose tissue, but had not reached the liver. Gallbladder wall was thickened. Lymph nodes along the hepatic artery in the hepatoduodenal ligament were detected with tumor metastasis using light microscopy.

\section{Histological features}

Microscopically, $>70 \%$ of the tumor was clear cells, which had large and well-defined cytoplasm borders (Figure 2). The clear cells were characterized by plentiful clear cytoplasm and distinct cell borders. The cells have large nuclei, prominent nucleoli, and little nuclear atypia. These cells were indistinguishable from hepatocellular adenocarcinoma and arranged in nests, sheets, and trabeculae (Figure 3). Conventional adenocarcinoma with enhanced mucin production was observed in the foci. Pathological examination of the lymph nodes along the hepatic artery revealed metastasis. The other lymph nodes revealed no metastasis. Interestingly, they showed skip metastasis, which spread to the hepatic artery lymph node without involvement of the hepatoduodenal ligament along the bile duct lymph node. There was no neural invasion or vascular invasion.

\section{Immunohistochemistry}

The lesion region of the tumor was strongly stained with antibodies to cytokeratin 19 (CK19), CK8, and CK18. Those cells with features of hepatocyte were diffusely stained for Hepatocyte Paraffin 1 (Figure 3), whereas alpha-fetoprotein (AFP)

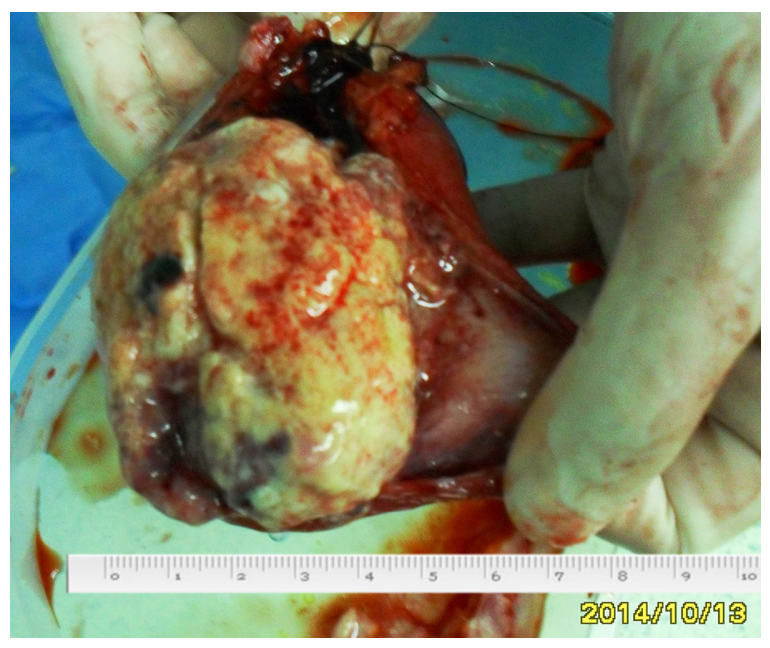

Figure 2 The sample of the resected CCG.

Note: The tumor consisted of lobulated, golden yellow mucus circumscribed, firm gray-red masses.

Abbreviation: CCG, cell adenocarcinoma of the gallbladder. staining was negative (Figure 3). Glypican 3 was strongly stained (Figure 3), which is usually significantly upregulated in hepatocellular carcinoma. Staining for HMB45 and smooth muscle actin was negative (Figure 3 ).

\section{Discussion}

CCG is a rare primary gallbladder neoplasm and has been characterized as a distinctive type of gallbladder tumor and extrahepatic bile ducts by WHO. ${ }^{1}$ CCG was first reported in 1926 by Tyson and Piney, ${ }^{5}$ in which they originally described a unique type of gallbladder tumor and named it as hypernephroma of the gallbladder. Since then, $<15$ cases have been reported. Vardaman and Albores ${ }^{6}$ examined 550 cases of gallbladder carcinoma and found that only six cases were CCG. Among them, only one case was described with hepatoid differentiation. Another was reported by Gakiopoulou et al, ${ }^{3}$ who described a solid adenocarcinoma with hepatoid features composed of large polygonal cells with mostly clear cytoplasm. CCG has a significant female preponderance. When diagnosed, the average age is 60 years. The current case describes the very first male patient with CCG.

Laboratory tests of tumor markers, such as CA19-9 and CEA, usually were positive. The AFP may also be positive. The pathomorphological feature of this case is papillary form, a protrusion to the gallbladder lumen growth. Papillary type has a lower tendency of direct invasion and lymph node metastasis. ${ }^{7}$ The histogenesis of CCG is supposed to arise from the epithelium. ${ }^{8}$ The anatomic location of the base of the tumor mass is usually at the body and the fundus of gallbladder. $^{6}$

Bittinger et $\mathrm{al}^{9}$ suggested that only when $>50 \%$ tumor cells show the clear cell differentiation, the tumor can be termed as CCG. The lesions are composed of clear cells with abundant cytoplasm and clear-cut cell borders. ${ }^{1}$ The cells are arranged in nests, glands, cords, or trabeculae, and contain prominent hyperchromatic nuclei with few cytological atypia, showing a solid, infiltrative growth pattern. ${ }^{9}$ Foci of classical adenocarcinoma are always seen in the tumor mass. The cytoplasm of most of the cells is rich in glycogen and sometimes contains vacuoles of mucin. ${ }^{10}$ However, many other malignant lesions may also show similar characteristics, such as metastatic clear cell renal carcinoma of the gallbladder, ${ }^{11-14}$ clear cell carcinoma of the ovary, ${ }^{15}$ endometrial clear cell carcinoma, ${ }^{16}$ the malignant clear cell sugar tumor of the lung, ${ }^{17}$ and other tumors with clear cell differentiation. The most important differential diagnosis is to distinguish renal clear cell carcinoma from hepatocellular carcinoma, especially with direct invasion of the liver. 

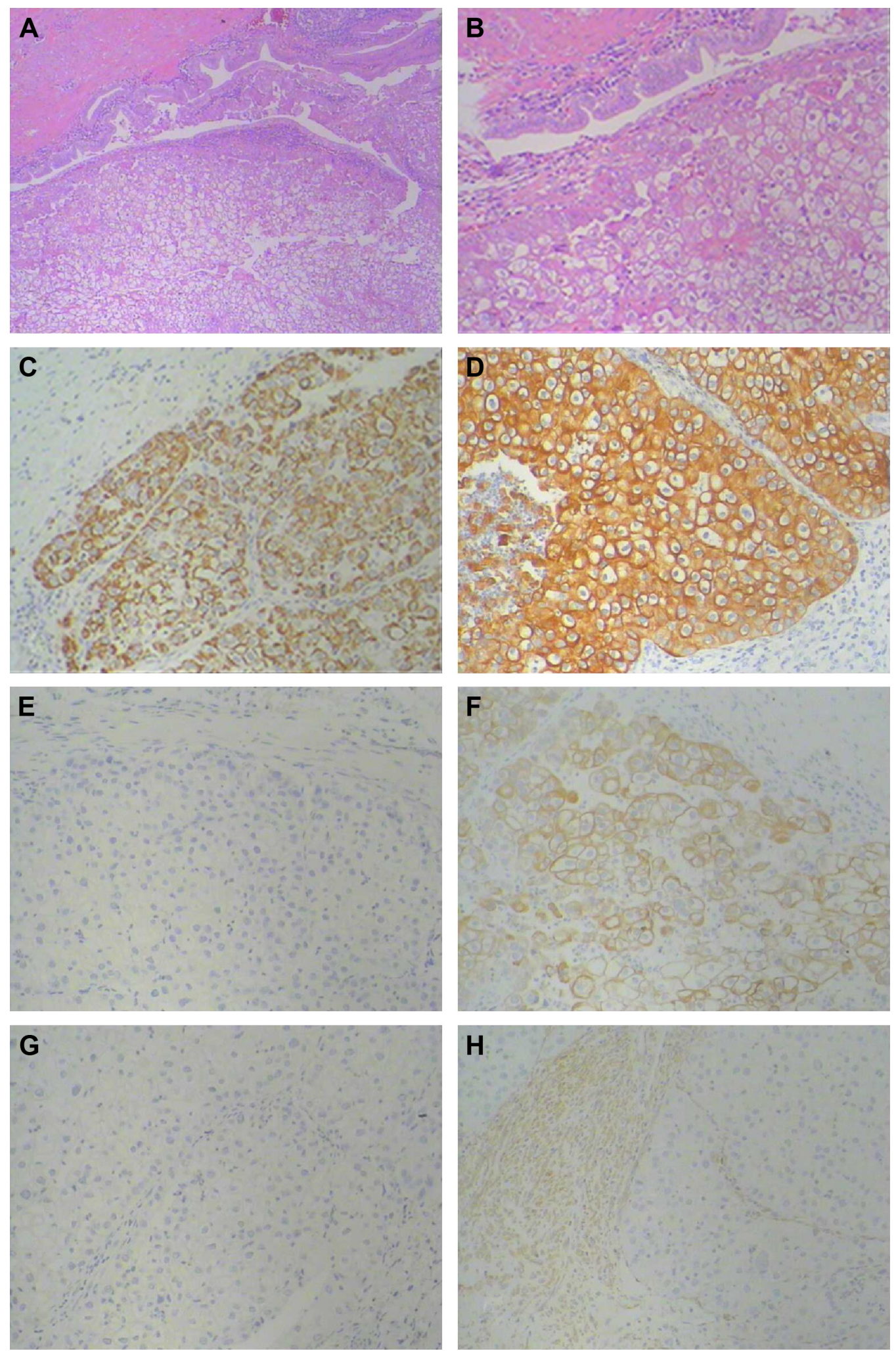

Figure 3 Histology of the CCG.

Notes: (A) Approximately $70 \%$ of the lesion is composed of clear cell (H\&E; original magnification $\times 40$ ). (B) Clear cell adenocarcinoma composed of cells with hepatoid differentiation. The tumor cells are arranged in a nested and trabecular pattern (H\&E; original magnification $\times 100)$. In immunohistochemical stain: (C) in the hepatoid areas, HepPar I immunoreactivity shows a coarse granular staining (H\&E; original magnification $\times 100)$, (D) the tumor cells are positive for CKI9 (H\&E; original magnification $\times 100)$, (E) the tumor cells are negative for AFP (H\&E; original magnification $\times 100$ ), (F) the tumor cells are positive for CK8-18 (H\&E; original magnification $\times 100)$, (G) the tumor cells are positive for GPC-3 (H\&E; original magnification $\times 100$ ), and $(\mathbf{H})$ the tumor cells are negative for SMA (H\&E; original magnification $\times 100$ ).

Abbreviations: CCG, cell adenocarcinoma of the gallbladder; H\&E, hematoxylin and eosin; HepPar I, Hepatocyte Paraffin I; CK, cytokeratin; AFP, alpha-fetoprotein; GPC-3, Glypican 3; SMA, smooth muscle actin. 
Table I Findings in previously reported cases of CCG with hepatoid differentiation

\begin{tabular}{|c|c|c|c|c|c|c|}
\hline Case & $\begin{array}{l}\text { Age } \\
\text { (years) }\end{array}$ & Gross features & $\begin{array}{l}\text { Hepatoid } \\
\text { differentiation }\end{array}$ & $\begin{array}{l}\text { Lymph node } \\
\text { metastases }\end{array}$ & Metastases & Follow-up \\
\hline Case $1^{6}$ & 66 & $7 \times 3 \times 2 \mathrm{~cm}$ & $\begin{array}{l}\text { Small foci in the } \\
\text { gallbladder; predominated } \\
\text { in the metastases sites }\end{array}$ & No & $\begin{array}{l}\text { The omentum, } \\
\text { multiple peritoneal }\end{array}$ & $\begin{array}{l}\text { Alive with disease (exact } \\
\text { survival time is not mentioned) }\end{array}$ \\
\hline Case $2^{3}$ & 76 & $2.5 \times 1.5 \times 0.5 \mathrm{~cm}$ & $\begin{array}{l}\text { Some parts of the } \\
\text { gallbladder }\end{array}$ & No & No & $\begin{array}{l}8 \text { months without recurrence by } \\
\text { the time of the case reported }\end{array}$ \\
\hline $\begin{array}{l}\text { Present } \\
\text { case }\end{array}$ & 80 & $7.1 \times 5.6 \times 4.6 \mathrm{~cm}$ & $\begin{array}{l}\text { Almost all the tumor } \\
\text { cells were composed of } \\
\text { clear cells }\end{array}$ & Yes & No & $\begin{array}{l}19 \text { months without recurrence } \\
\text { by the time of the case reported }\end{array}$ \\
\hline
\end{tabular}

Abbreviation: CCG, cell adenocarcinoma of the gallbladder.

As shown in the abdominal CT scan, there were no other lesions in the kidney, except the renal cyst. So it can rule out the diagnosis of renal clear cell carcinoma. Well-differentiated cells with the characteristic of classical adenocarcinoma and severe dysplasia in the adjacent mucosa support the diagnosis of primary carcinoma. In order to determine the histological subtype, immunohistochemistry can play a certain role. CEA and CK7 were stained strongly in gallbladder but were negative in nearly all other clear cell carcinomas, such as the renal, ovary, liver, and the endometrium. So making the correct diagnosis is of some help. In our case, the cell was indistinguishable from the hepatocellular carcinoma by the microscope, and the immunohistochemistry showed a strong positivity for Hepatocyte Paraffin 1, which is mainly expressed in the hepatocyte. The AFP and glypican 3 were negative, whereas the CK19 was positive, which suggested that the tumor originated from epithelium of the gallbladder and had a hepatoid differentiation. The common embryonic origin could explain the neoplasm of the gallbladder and liver that have similar morphological features and antigenic properties. ${ }^{6,18}$ The literature review indicated that this is the first case of primary CCG with widely hepatoid differentiation. Only two cases of CCG with hepatoid differentiation have been previously reported that are summarized in Table 1. Vardaman and Albores ${ }^{6}$ described a case in which the tumor was metastasized to multiple peritoneal and the omentum sites at the time of diagnosis and showed widely hepatoid differentiation in the metastasis sites. While in the primary tumor site, the gallbladder, only small foci of hepatoid differentiation were observed. Detailed follow-up information is not known, because the report just described that the patient was still alive with disease at the time of publication. Another case reported by Gakiopoulou et al ${ }^{3}$ described a 76-year-old female patient who underwent operation for cholelithiasis and was diagnosed with hepatoid adenocarcinoma at the time of pathological diagnosis. They pointed out that a firm whitish solid tumor measuring $2.5 \times 1.5 \times 0.5 \mathrm{~cm}$ was observed, with areas of hepatoid adenocarcinoma composed of clear cells. It was proved that there was no recurrence by the time this case was reported (8 months postoperatively).

A review of previously reported CCG shows that all the cases were limited by lack of a detailed description of survival time and death due to disease in a relatively short period. There was no indication of adjuvant chemotherapy, and no literature has been reported on the application of chemotherapy. In general, the prognosis of CCG is poor and surely determined by the disease stage. In our case, the patient refused chemotherapy and by the time the case was reported, the patient was still free of recurrence 18 months after radical resection. The long-term outcome was still observed in the follow-up. Hence, we can conclude that CCG with hepatoid differentiation when compared with the outcomes and prognosis of patients with CCG has a better outcome in time to overall survival, especially when treated with gallbladder radical resection. Therefore, for patients with CCG with hepatoid differentiation, surgical resection is the only potentially curative therapy.

\section{Conclusion}

Although CCG with hepatoid differentiation is a very rare malignant neoplasm, awareness of its existence and an efficient immunohistochemical marker panel for the diagnosis of CCG will be very helpful in the differential diagnosis, especially in order to avoid misdiagnosis as metastatic hepatocellular carcinoma.

\section{Acknowledgments}

The authors thank Pan Pan for her valuable discussion. Lei Zhao is funded by 2015 Innovation and Creation Fund of Shandong Academy of Medical Science.

\section{Disclosure}

The authors report no conflicts of interest in this work. 


\section{References}

1. Albores-Saavedra J, Molberg K, Henson DE. Unusual malignant epithelial tumors of the gallbladder. Semin Diagn Pathol. 1996;13(4): 326-338.

2. Albores-Saavedra J, Henson DE, Sobin LH. The WHO histological classification of tumors of the gallbladder and extrahepatic bile ducts. A commentary on the second edition. Cancer. 1992;70(2):410-414.

3. Gakiopoulou H, Givalos N, Liapis G, Agrogiannis G, Patsouris E, Delladetsima I. Hepatoid adenocarcinoma of the gallbladder. Dig Dis Sci. 2007;52(12):3358-3362.

4. van den Bos IC, Hussain SM, Dwarkasing RS, et al. Hepatoid adenocarcinoma of the gallbladder: a mimicker of hepatocellular carcinoma. Br J Radiol. 2007;80(960):e317-e320.

5. Tyson W, Piney A. Hypernephroma of the gallbladder: cholecystectomy. Br J Surg. 1926;13:757-759.

6. Vardaman C, Albores SJ. Clear cell carcinomas of the gallbladder and extrahepatic bile ducts. Am J Surg Pathol. 1995;19(1):91-99.

7. Misra S, Chaturvedi A, Misra NC, Sharma ID. Carcinoma of the gallbladder. Lancet Oncol. 2003;4(3):167-176.

8. Laitio M. Histogenesis of epithelial neoplasms of human gallbladder II. Classification of carcinoma on the basis of morphological features. Pathol Res Pract. 1983;178(1):57-66.

9. Bittinger A, Altekrüger I, Barth P. Clear cell carcinoma of the gallbladder: a histological and immunohistochemical study. Pathol Res Pract. 1996;191(12):1259-1265.
10. Vaillo A, Ballestin C, Ruiz Liso JM. Fine needle aspiration cytology of clear cell carcinoma of the gallbladder with hepatic infiltration: a case report. Acta Cytol. 2004;48(4):560-564.

11. Chung PH, Srinivasan R, Linehan WM, Pinto PA, Bratslavsky G. Renal cell carcinoma with metastases to the gallbladder: four cases from the National Cancer Institute (NCI) and review of the literature. Urol Oncol. 2011;30(4):476-481.

12. Aoki T, Inoue K, Tsuchida A, et al. Gallbladder metastasis of renal cell carcinoma: report of two cases. Surg Today. 2002;32(1):89-92.

13. Win AZ. Renal cell carcinoma metastasis to the gallbladder detected by FDG-PET/CT. J Clin Med Res. 2014;6(6):482-486.

14. Ghaouti M, Znati K, Jahid A, et al. A gallbladder tumor revealing metastatic clear cell renal carcinoma: report of case and review of literature. Diagn Pathol. 2013;8(1):145-149.

15. Prasenjit D, Geetika S, Narender K, et al. Clear cell carcinoma of ovary with squamous metaplasia: a unique histopathological observation. Indian J Med Paediatr Oncol. 2011;32(3):177-179.

16. Oluwole F, Katja G, Desouki MM, et al. The clinicopathologic significance of p53 and BAF-250a (ARID1A) expression in clear cell carcinoma of the endometrium. Mod Pathol. 2013;26(8):1101-1110.

17. Ting Y, Haiquan C, Hong H, et al. Malignant clear cell sugar tumor of the lung: patient case report. J Clin Oncol. 2010;28(31):626-628.

18. $\mathrm{Ng} \mathrm{WK}, \mathrm{Ng}$ WF. Elevated serum alpha-fetoprotein in a patient with undifferentiated carcinoma of the gall bladder. J Clin Pathol. 1995; 48(11):1061-1063.
OncoTargets and Therapy

\section{Publish your work in this journal}

OncoTargets and Therapy is an international, peer-reviewed, open access journal focusing on the pathological basis of all cancers, potential targets for therapy and treatment protocols employed to improve the management of cancer patients. The journal also focuses on the impact of management programs and new therapeutic agents and protocols on

\section{Dovepress}

patient perspectives such as quality of life, adherence and satisfaction. The manuscript management system is completely online and includes a very quick and fair peer-review system, which is all easy to use. Visit http://www.dovepress.com/testimonials.php to read real quotes from published authors. 